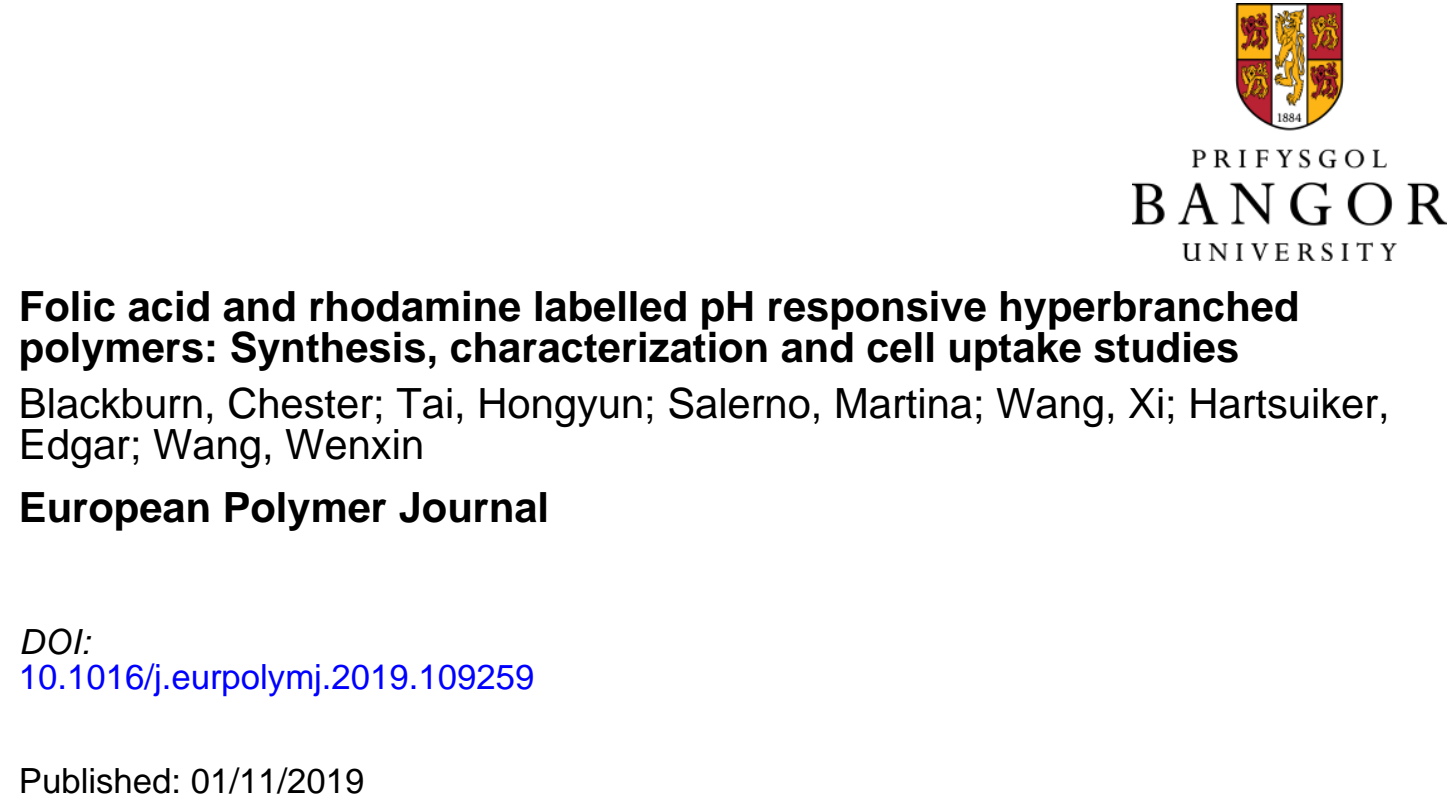

Folic acid and rhodamine labelled pH responsive hyperbranched polymers: Synthesis, characterization and cell uptake studies

Blackburn, Chester; Tai, Hongyun; Salerno, Martina; Wang, Xi; Hartsuiker, Edgar; Wang, Wenxin

\section{European Polymer Journal}

DOI:

10.1016/j.eurpolymj.2019.109259

Published: 01/11/2019

Peer reviewed version

Cyswllt i'r cyhoeddiad / Link to publication

Dyfyniad o'r fersiwn a gyhoeddwyd / Citation for published version (APA):

Blackburn, C., Tai, H., Salerno, M., Wang, X., Hartsuiker, E., \& Wang, W. (2019). Folic acid and rhodamine labelled pH responsive hyperbranched polymers: Synthesis, characterization and cell uptake studies. European Polymer Journal, 120, [109259].

https://doi.org/10.1016/j.eurpolymj.2019.109259

\footnotetext{
Hawliau Cyffredinol / General rights

Copyright and moral rights for the publications made accessible in the public portal are retained by the authors and/or other copyright owners and it is a condition of accessing publications that users recognise and abide by the legal requirements associated with these rights. study or research.

- Users may download and print one copy of any publication from the public portal for the purpose of private

- You may not further distribute the material or use it for any profit-making activity or commercial gain

- You may freely distribute the URL identifying the publication in the public portal?
}

Take down policy

If you believe that this document breaches copyright please contact us providing details, and we will remove access to the work immediately and investigate your claim. 


\title{
Folic Acid and Rhodamine Labelled pH Responsive Hyperbranched Polymers: synthesis, characterization and cell uptake studies
}

\author{
Chester Blackburn ${ }^{1}$, Hongyun Tai ${ }^{*}$, Martina Salerno ${ }^{2}, \mathrm{Xi}_{\text {Wang }}{ }^{3}$, Edgar Hartsuiker ${ }^{2}$ and Wenxin \\ Wang*3 \\ 1 School of Natural Sciences, Bangor University, Deiniol Road, Bangor, Gwynedd LL57 2UW, UK \\ 2 NWCR Institute, School of Medical Sciences, Bangor University, Deiniol Road, Bangor, Gwynedd LL57 2UW, \\ UK \\ 3 Charles Institute of Dermatology, School of Medicine, University College Dublin, Dublin 4, Ireland. \\ * Correspondence: h.tai@bangor.ac.uk; wenxin.wang@ucd.ie
}

Received: date; Accepted: date; Published: date

\begin{abstract}
Here, we report the synthesis of novel folated and fluorescent labelled $\mathrm{pH}$ responsive hyperbranched polymers (HBPs) via reversible addition fragmentation chain-transfer (RAFT) copolymerization of 2-propyl acrylic acid (PAA), 2-(dimethylamino) ethyl methacrylate (DMAEMA) and disulfide diacrylate (DSDA) using 4-cyano-4-(((dodecylthio)carbonothioyl)thio)pentanoic acid (CDCTPA) as RAFT agent and post functionalization via bioconjugation techniques. The resultant HBPs were characterized by Nuclear Magnetic Resonance Spectroscopy (NMR) and Size Exclusion Chromatography (SEC). Dynamic Light Scattering (DLS) technique was used to measure the size changes of HPBs in solutions at different $\mathrm{pH}$ values to demonstrate $\mathrm{pH}$ responsiveness of the polymers. The cell uptake evaluations on these folated and fluorescent labelled HBPs were carried out using HeLa cell line and confirmed by confocal images. The results show that we have successfully synthesized the desired multifunctional hyperbranched poly (PAA-co-DMAEMA-co-DSDA) with a pH responsive characteristic and the potentials for use as a drug delivery vehicle.
\end{abstract}

Keywords: hyperbranched polymers; pH responsive; RAFT polymerization; targeted delivery, cell uptake

\section{Introduction}

Cancer is regarded globally as a major burden on the medical sector, with an estimated 14.1 million new cases diagnosed in 2012[1], whilst in 2018 it is estimated that there will be an increase in incidence with an estimated 18.1 million new cancers[2]. Cancerous tumors are generally regarded as being either benign or malignant, where benign tumors are usually operated on and removed from the patient, if the factors such as: the type of cancer (e.g. pancreatic, lung, mouth); the size of the tumor and stage of progression, the locale of the tumor and the general health of the patient are all considered and are deemed to be suitable for operation by the physician. Should the tumor present itself as inaccessible, particularly aggressive (as is seen in late stage cancers) or inoperable, as is the case for leukemia or lymphoma; radiotherapy, chemotherapy or a combination of both is used to treat the cancerous site. Conventional chemotherapeutics such as doxorubicin and gemcitabine however, suffer from low efficacy and high toxicity, and in most cases these properties lead to side effects and widely associated with cancer treatments such as: hair loss[3], fatigue[4], sickness[5], and heightened sensitively to infection due to a lowered immune system[6].

It was hypothesized that the distinct changes in the tumorous environment, namely, a lowered $\mathrm{pH}$ (ca. -0.5) and an increased temperature $\left(\mathrm{ca}+1^{\circ} \mathrm{C}\right)$ when compared to healthy physiological conditions can be attributed to these tissues producing energy almost exclusively via anaerobic glycolysis, followed by the fermentation of lactic acid, even with an abundance of oxygen[7,8]. Furthermore, it is widely accepted that the folate receptor (FR) is a confirmed antigen associated with tumorous cells, displaying overexpression within these tissues[9,10]. This antigen binds folate and folate drug conjugates with exceptional efficiency, and via endocytosis internalizes these molecules into the cell in question[11]. 
For instance Wang et al. designed a [ $\left.{ }^{111} \mathrm{In}\right]$-DPTA-folate molecule for use as chemotherapeutic diagnostic, exploiting the overexpression of FR these cells display. They demonstrated that radiotracer uptake can be observed in both tumor and the accumulation in kidneys[12]. Additionally, the FR has been exploited to allow for low molecular weight chemotherapeutics[13,14], immune therapeutics[9], liposomes[15,16] and drug encapsulated nanoparticles[17] to be successful in delivering payload to the selected site.

Stimuli responsive polymers have garnered a great deal of scientific interest over the years due to their ability to respond sharply to even minor changes in external environments, such as $\mathrm{pH}$ and temperature, leading to conformation changes (hydrophilic to lipophilic), changes to overall zeta potential, and release of guest molecules[18-20]. Other techniques have been employed to impart a $\mathrm{pH}$ responsive nature such as in polymer drug conjugates. For instance, Rodrigues et al developed an acid-sensitive PEG conjugate of doxorubicin with cleavable hydrazone linkage. Utilizing fluorescent techniques the distribution of the drug was found to be within the cytoplasm of the LXFL 529 cancer cells, as oppose to the free drug which had accumulated predominately in the nucleus[21]. Hyperbranched polymers, as oppose to their linear counterparts, display characteristics desirable for drug delivery systems such as: high solubility, low solution viscosity and a high number of terminal functional groups that can be exploited for further chemical modification[22-25]. Furthermore, through careful design of polymer architecture, post reaction modification can be performed introducing bioactive moieties such as cell penetrating peptides or small molecules that can induce endocytosis such as folic acid $[26,27]$. Notably, Hu and co-workers developed cell penetrating hyperbranched polyprodrug amphiphiles that upon internalization via endocytosis into the cell there is a reductive milieu-actuated release of their camptothecin prodrug, in the active form, with greater than 70 fold increase in cytotoxity. Additionally, caging of a Gd complex inside their polyprodrug allowed for the additional benefit of magnetic resonance imaging, demonstrating a platform for chemotherapeutic and imaging capabilities synergistically[28]. Additionally, Lee et al developed a double hydrophilic hyperbranched block co-polymer poly-(ethylene oxide)-hyperbranched-poly glycerol (PEO- $h b$-PG) that upon conjugation with doxorubicin formed micellar structures, Conjugation via the previously mentioned hydrazone linkage allowed this structure to control release within cells as confirmed via confocal images and an increased toxicity on the HeLa cell line confirmed via MTT assay[29]. These characteristics have led to stimuli responsive hyperbranched polymers becoming a desirable choice for the development of drug and gene delivery systems[30-33].

We previously synthesized hyperbranched $\mathrm{pH}$ responsive co-polymer using 2-propyl acrylic acid (PAA) and polyethylene glycol diacrylate (PEGDA) via reversible addition fragmentation chain transfer polymerization (RAFT), and this structure was found to respond sharply to acidic environments[34]. Hemolysis studies indicated that at physiological conditions ( $\mathrm{pH} 7.4)$ no activity was found however, $90 \%$ activity was discovered at $\mathrm{pH}$ 5.8. This activity was attributed to the PAA moieties within the structure. It is understood that Poly (PAA) is an acid responsive homopolymer, due to the polyelectrolyte nature of the material. At a low $\mathrm{pH}(<6)$ the polymer forms a compact hypercoiled structure, whereas when the $\mathrm{pH}$ is raised it is ionized and the structure becomes solvated and adopts a more open coiled conformation[35,36]. Yin and co-authors synthesized co-polymer of PAA and $\mathrm{N}$-isopropylacrylimide (NIPAM) to yield Poly (NIPAM-co-PAA) utilizing both the $\mathrm{pH}$ responsive nature of PAA alongside the well-studied temperature responsive properties of PNIPAM. It was found that in dilute solutions sharp transitions within the $\mathrm{pH}$ range 5-6 were observed. This was attributed to the ionization of the carboxylic acid group via protonation and further by temperature dependent phase separation by the Poly (NIPAM) segments[37]. In this work, we aim to produce PAA based $\mathrm{pH}$ responsive hyperbranched co-polymers, with an additional benefit of reducibility via the introduction of a disulfide diacrylate moiety (DSDA). Through the introduction of a divalent disulfide bond within a symmetrical multi-vinyl monomer (MVM), the branching properties afforded via the use of other MVMs such as PEGDA can be retained whilst reduction can occur in situ allowing biodegradable properties[24]. For instance, the disulfide bond is known to be susceptible to attack by both electrophiles and nucleophiles, and therefore a variety of reducing agents can be used to convert from a disulfide, or thiocarbonates, into the corresponding thiol groups[24,27,38-40], whilst also it has been displayed by Zhao et al. that degradation of their DMAEMA-DSDA hyperbranched co-polymer proceeded at a much higher rate with the introduction of 
glutathione[41]. This response therefore, leads this monomer as a highly desirable building block for drug delivery vehicles due to biodegradable properties.

Controlled radical polymerization techniques such as atom transfer radical polymerization (ATRP)[42-44], nitroxide mediated polymerization (NMP) [45,46] and the aforementioned RAFT[47-49] allow greater control over polymerization than conventional free radical polymerization. This control allows the synthesis of polymers with complex topologies, control over molecular weight and desirable narrow poly dispersity $(\Theta)$. RAFT particularly allows control over the synthesis by addition of only RAFT agent into the mixture of monomers, initiator and solvent if desired. As opposed to other controlled methods such as ATRP, there is no need for transition metal catalysts to be present to afford such control, which have their own toxicity concerns associated with them. Additionally, RAFT agents can be fine-tuned to meet the needs of specific systems thus affording RAFT polymerization the advantage of being compatible with a broad range of monomers. Furthermore, RAFT agent end groups are found at the terminus of dormant polymer chains, this yields the advantages for post modifications of the structure, that were previously not possible due to lack of appropriate functional groups within desired monomer repeating units.

This work aims to take the advantages of controlled radical polymerization technique (RAFT) and folate targeted drug delivery, in order to increase payload efficacy, whilst also limiting toxicity to the surrounding environment. Co-polymerization of three monomers 2-propyl acrylic acid (PAA), 2(dimethylamino) ethyl methacrylate (DMAEMA) and disulfide diacrylate (DSDA) was performed (Scheme 1) and the resultant HBPs exhibited a desired $\mathrm{pH}$ response demonstrated by dynamic light scattering (DLS). In addition, Steglich esterifications via the N-hydroxy succinimide/ dicyclohexylcarbodiimide (NHS/DCC) coupling reaction were performed to functionalize the resultant HBPs with targeting ligand (folic acid) and fluorescent tag (Rhodamine B ethylenediamine) for in vitro uptake studies on the HeLa cell line.

\section{Materials and Methods}

\subsection{Materials}

All solvents were purchased from Fisher Scientific as analytical grade and used as received. Diethyl propyl malonate (Alfa aesar 99\%), 2-2'-disulfanediylbis(ethan-1-ol) (90\% technical grade), diisopropyl azodicarboxylate (DIAD) (alfa aesar 94\%), triphenylphosphine (ACROS Organics 99\%), hydrazine hydrate $55 \%$ (35\% hydrazine) (ACROS Organics) and folic acid (Fisher bioreagents) were all purchased from Fisher Scientific and used as received.

2-(Dimethylamino)ethyl methacrylate (98\%), 4-4'-azobis(4-cyanovaleric acid) (98\%), Kolisov PEG400, phthalmide (99\%), ethylene diamine (99\%), BOC anhydride (97\%), N-hydroxy succinimide (NHS 98\%), dicyclohexylcarbodiimide (DCC 99\%), tri-fluoroacetic acid (TFA 99\%) and rhodamine B were all purchased from Sigma Aldrich and used as received.

4-cyano-4-(((dodecylthio)carbonothioyl)thio)pentanoic acid (CDCTPA) was synthesized according to published method[50].

Dialysis tubing (regenerated cellulose) 2KDa cut off was purchased from Spectrum Labs and were stored in water in the fridge before use.

Dulbecco's minimum essential medium, Dulbecco's phosphate buffered saline (DPBS), penicillin, streptomycin, L-glutamine, fetal bovine serum (FBS), DAPI (4',6-diamidino-2-phenylindole), bovine serum albumin (BSA) and Immu-Mount were all purchased from Sigma Aldrich to the highest possible grade (suitable for cell culture) and were sterilized before use. HeLa cell line was kindly donated to the project by Dr. Chris Staples at the North Wales Cancer Research Institute at the school of medical science in Bangor University.

\subsection{Experimental methods}

\subsection{1 ${ }^{1} \mathrm{H}$ Nuclear Magnetic Resonance $\left({ }^{1} \mathrm{H}\right.$ NMR)}


${ }^{1} \mathrm{H}$ NMR were run on a $400 \mathrm{MHz}$ Bruker ultra-shield NMR machine loaded with topspin software for 16

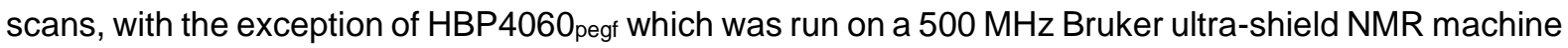
loaded with topspin software for 512 scans.

\subsubsection{Synthesis of monomers and diamine linkers}

2-Propyl acrylic acid (PAA) was synthesized using the method reported by Ferritto and Tirell [42]. Disulfanediylbis(ethane-2,1-diyl) diacrylate (DSDA) was synthesized via the reported method from Huang et al.[51]. Diamine linkers were synthesized using the method reported by D'Arcy et al [44], with subsequent mono- BOC protections adapted from Muller et al [45]. Full experimental information and reaction schemes for the synthesis of these compounds can be found in the corresponding "data in brief article[52]"

\subsubsection{Hyperbranched polymer synthesis}

All reagents and solvent according to Table 1 were added into a $10 \mathrm{ml}$ reaction vial equipped with open top cap sealed with PTFE septa. Stirring speed was set to $300 \mathrm{rpm}$ and the reaction vials were purged with nitrogen for 20 minutes. Reactions were heated to $65^{\circ} \mathrm{C}$ and left to polymerize for $18 \mathrm{hrs}$ under nitrogen protection. Reactions were quenched at a set time of $18 \mathrm{hrs}$ was reached in all cases. Polymers were purified by precipitation once into 8:2 hexane: diethyl ether mixture and then a further two times into pure ether. Drying was performed in a vacuum oven for $24 \mathrm{hrs}$ at $37.5^{\circ} \mathrm{C}$.

\subsubsection{Determination of average molecular weight by Size Exclusion Chromatography (SEC)}

SEC analysis was performed using an Aligent 1260 Infinity machine equipped with Polargel-M organic column with DMF as the eluent solvent system (additive $0.1 \% \mathrm{w} / \mathrm{v} \mathrm{LiBr}$ ). Flow rate was set at $1 \mathrm{ml} / \mathrm{min}$ and Refractive Index (RI) detector was used while the operating temperature was $40^{\circ} \mathrm{C}$. poly(methyl methacrylate) PMMA was used as the calibration standard.

\subsubsection{Particle size measurements}

Particle size measurements were performed on a Malvern Zetasizer $1000 \mathrm{Hsa}$ at $25^{\circ} \mathrm{C}$ with a $90^{\circ}$ front scatter laser $(633 \mathrm{~nm})$ at Wrexham Glyndwr University. The data were analyzed using PCS v1.61 software package and CONTIN regularization algorithm method. Briefly, HBP4060 and HBP4060 pegf were dissolved in distilled water either at $\mathrm{pH} 7.4,6.8$ or 5.4 , while at a concentration of $0.1 \%(\mathrm{w} / \mathrm{v})$. Measurements were made in a $10 \mathrm{~mm}$ polystyrene cuvette with $99 \%$ transparency and were blown with compressed air before addition of solution to avoid dust contamination. Cuvettes were allowed to equilibrate within the machine for 15 mins before sizing experiments were performed.

\subsubsection{Conjugation of folic acid onto polymer}

The amount of $\mathrm{COOH}$ on HBP4060 Polymer was determined via ${ }^{1} \mathrm{H}$ NMR. For folic acid conjugation, $0.3 \mathrm{~g}$ of polymer (containing $2.5 \mathrm{mmol}$ of $\mathrm{COOH}$ groups) was dissolved in $5 \mathrm{ml}$ DMF and DCC (3.2 $\mathrm{mmol}, 0.65 \mathrm{~g}, 1.5 \mathrm{eq})$ and NHS $(3.2 \mathrm{mmol}, 0.36 \mathrm{~g}, 1.5 \mathrm{eq})$ was added and the reaction was left to stir for 2 hours in the dark at 30 degrees. Simultaneously, folic acid $(0.65 \mathrm{~g}, 1.49 \mathrm{mmol})$ was dissolved in 5 $\mathrm{ml} \mathrm{DMF} \mathrm{and} \mathrm{DCC}(0.6 \mathrm{~g}, 2.9 \mathrm{mmol})$ and NHS $(0.34 \mathrm{~g}, 2.9 \mathrm{mmol})$ were added and the reaction was left to stir in the dark at 30 degrees. Upon formation of the dicyclohexylurea precipitate the two mixtures were added together and ethylene diamine added $(0.36 \mathrm{~g}, 6 \mathrm{mmol})$ allowed to stir in the dark overnight. In the case of PEG400 linked folate, folic acid was substituted for folate-PEG-NH $2(0.2 \mathrm{~g} 0.2 \mathrm{mmol})$ and this was dissolved in $5 \mathrm{ml}$ DMF and left to stir alongside DCC $(0.06 \mathrm{~g}, 0.3 \mathrm{mmol})$ and NHS $(0.03 \mathrm{~g}, 0.3$ $\mathrm{mmol}$ ). Purification was performed using dialysis (regenerated cellulose $2 \mathrm{KDa}$ cut off Spectrum Labs) over 4 days in a 5:95 DMF: $\mathrm{H}_{2} \mathrm{O}$ system (v/v) with system changes every 24 hours. The resultant liquid was then freeze-dried to yield polymer folate conjugate of either $\mathrm{HBP} 4060$ ethylf as a yellow powder $(30 \%$ wt. yield) or HBP4060 pegf as a dark orange/brown powder (80\% wt. yield).

\subsubsection{Conjugation of rhodamine $B$ ethylene diamine onto polymers}


For HBP4060, 30mg of HBP4060 (ca $0.25 \mathrm{mmol} \mathrm{COOH}$ ) was dissolved in $2 \mathrm{ml}$ DMF in a $10 \mathrm{ml}$ reaction vial. To this solution, NHS (4 mg, $0.03 \mathrm{mmol})$ and DCC $(6 \mathrm{mg}, 0.03 \mathrm{mmol})$ were added and the solution was stirred in the dark at ambient temperature for $2 \mathrm{hrs}$. For HBP4060pegf, $30 \mathrm{mg}$ of HBP4060pegf (ca $0.2 \mathrm{mmol} \mathrm{COOH}$ ) was dissolved in $2 \mathrm{ml} \mathrm{DMF}$ in a $10 \mathrm{ml}$ reaction vial. To this solution, NHS ( $3 \mathrm{mg}, 0.024$ $\mathrm{mmol}$ ) and DCC (5 mg, $0.024 \mathrm{mmol})$ were added and the solution was stirred in the dark at ambient temperature for $2 \mathrm{hrs}$.

Following the above procedures, rhodamine $B$ ethylene diamine $(10 \mathrm{mg}, 0.002 \mathrm{mmol})$ was added to each solution containing either HBP4060 or HBP4060pegf. Then the vial was submerged into a sand bath protected from light and heated to $30^{\circ} \mathrm{C}$ and left to react overnight. The solution was then subjected to dialysis (regenerated cellulose 2KDa cut off Spectrum Labs) in a 5:95 DMF: $\mathrm{H}_{2} \mathrm{O}$ system (v/v) with system changes every 24 hours, until the solvent system was colorless (4 days for HBP4060 pegr and 5 days for HBP4060). After freeze drying, the products appeared as an orange powder (HBP4060 pegfR yield 33\% wt.) and a red powder (HBP4060R yield 60\% wt.). Characterization was performed via UVVis absorption spectroscopy in DMF at $554 \mathrm{~nm}$.

\subsubsection{Quantification of folate on polymers}

UV-Vis electron absorption spectra were recorded using a Perkin Elmer Lambda 35 UV/Vis spectrophotometer in $10 \mathrm{~mm}$ Quartz cells in DMF at ambient temperature, and used for quantification of the amount of folate linked onto polymers. Calibration curve of folate was established between 5000 $50000 \mathrm{ng} / \mathrm{ml}$ at $362 \mathrm{~nm}$ to give a resultant $R^{2}$ value of 0.9688 .

\subsubsection{Quantification of rhodamine on polymers}

UV-Vis electron absorption spectra were recorded using a Shimadzu UV-3600 spectrophometer in 10 $\mathrm{mm}$ polystyrene cells in distilled water at ambient temperature, and used for quantification of the amount of rhodamine linked onto polymers. Calibration curve of rhodamine was created between $300 \mathrm{ng} / \mathrm{ml}-50$ $\mathrm{ng} / \mathrm{ml}$ at $554 \mathrm{~nm}$ to give a resultant $R^{2}$ value of 0.9975 .

\subsubsection{Cell uptake evaluations visualized by confocal microscopy}

Polymers labelled with folate either via ethylene diamine (HBP4060 $\left.0_{\text {ethyf }}\right)$ or PEG400 diamine (HBP4060 pegf $_{\text {) }}$ and unlabeled polymers (HBP4060) were dissolved into appropriate concentrations overnight in Dulbecco's phosphate buffered saline. Samples were then filtered through a $0.2 \mu \mathrm{m}$ membrane filter for sterilization. HeLa cells were cultured in Dulbecco's Minimum Essential Medium (DMEM) with $10 \%$ FBS $2 \mathrm{mM}$ glutamine and $100 \mathrm{U}$ penicillin with $0.1 \mathrm{mg} / \mathrm{ml}$ streptomycin until they reached $70-80 \%$ confluency and were plated on coverslips in a 24 well plate at roughly $80 \mathrm{~K}$ cells per well at $500 \mu \mathrm{l}$ overall volume and were left to proliferate for $24 \mathrm{hrs}$. Rhodamine labelled polymers, sterile water, rhodamine B $(100 \mu \mathrm{g} / \mathrm{ml})$ and Dulbecco's phosphate buffered saline controls were then added to ensuring the same volume was added into each well in and were left to incubate for $1 \mathrm{hr}$. Afterwards the solution was aspirated and washed with PBS. $4 \%$ para formaldehyde solution in PBS was then added and left for 10 mins before being aspirated. Then a successive wash with PBS was performed, aspirated and then washed with PBS again. 0.1\% (v/v) DAPI (4',6-diamidino-2-phenylindole) in BSA (Bovine Serum Albumin) was then added and left to stain for 10 mins, before being aspirated, and the coverslips removed and washed with sterile water before mounting on microscope slides (ImmuHistoMount). Confocal images were taken on a Zeiss LSM710 confocal microscope using 63x oil magnification objective lens, with ZEN Black software. For DAPI visualization $405 \mathrm{~nm}$ laser was used for excitation and Rhodamine $561 \mathrm{~nm}$ excitation laser.

\section{Results and Discussion}

\subsection{Synthesis and characterization of $\mathrm{pH}$ responsive hyperbranched co-polymers}


Hyperbranched co-polymers were synthesized utilizing the well-established Reversible Addition Fragmentation Chain Transfer (RAFT) polymerization approach from the monomers 2-propyl acrylic acid (PAA) and 2-(dimethylamino) ethyl methacrylate (DMAEMA) as well as redox sensitive branching co-monomer DSDA due to the presence of disulfide bond, in varying ratios (Table 1). 4,4'- azobis (4cyanovaleric acid) (ACVA) was adopted as the radical initiator, whilst 4-cyano-4(((dodecylthio)carbonothioyl)thio)pentanoic acid CDCTPA was chosen as the RAFT agent (Scheme 1). Reactions were performed until a visible increase in viscosity of the reaction media was noted (in all cases this was found to be ca. $18 \mathrm{hrs}$ ) garnering yields between $60-67 \%$ (wt. \%) for all reactions. The change in viscosity was not measured by quantitative means. As stated in the experimental section, the stirrer bar at the beginning of the reaction was spinning unhindered (stirring rate set as 300RPM), however, at the specified time (18 hrs) spinning was no longer possible. 

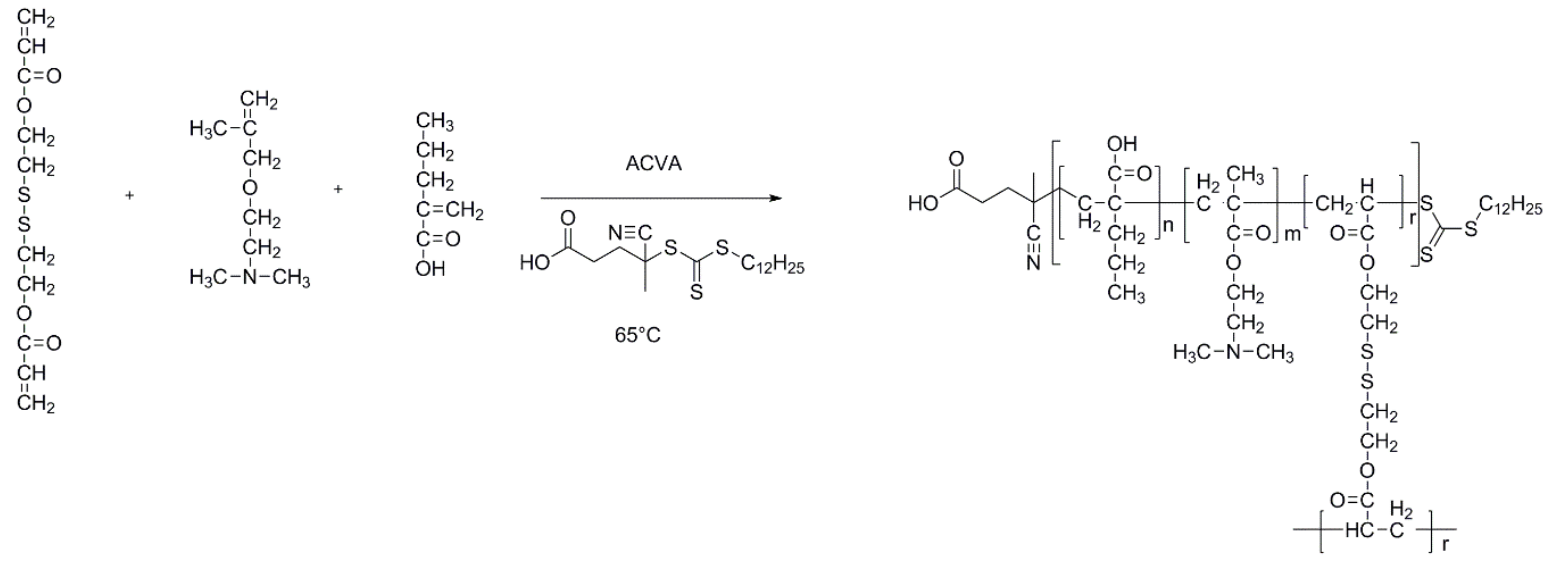

Scheme 1. Synthesis of hyperbranched co-polymers via reversible addition fragmentation chain transfer (RAFT) polymerization of 2-(dimethylamino) ethyl methacrylate (DMAEMA), disulfide diacrylate (DSDA), and 2-propyl acrylic acid (PAA). CDCTPA was used as the RAFT agent, while 4,4'-azobis-(4cyanovaleric acid) (ACVA) was used as the initiator.

Table 1: Experimental conditions for the Synthesis of $\mathrm{pH}$ responsive hyperbranched polymers from RAFT copolymerizations of PAA, DMAEMA and DSDA at $65^{\circ} \mathrm{C}$ in THF and the results from SEC analysis.

\begin{tabular}{|c|c|c|c|c|c|c|c|c|}
\hline \multirow[t]{3}{*}{ Entry } & \multirow{3}{*}{$\begin{array}{l}\text { Polymer } \\
\text { Sample }\end{array}$} & \multirow[t]{3}{*}{$F^{A}$} & \multirow{3}{*}{$\begin{array}{l}\mathrm{RT}^{\mathrm{B}} \\
\text { (Hrs.) }\end{array}$} & \multirow{3}{*}{$\begin{array}{c}\text { Yield } \\
\text { (wt. \%) }\end{array}$} & \multicolumn{4}{|c|}{ SEC RI } \\
\hline & & & & & & $\mathrm{Mw}_{\mathrm{w}} \mathrm{C}$ & $\mathrm{Mn}^{\mathrm{D}}$ & $\oslash^{\mathrm{E}}$ \\
\hline & & & & & & $\mathrm{KDa}$ & $\mathrm{KDa}$ & \\
\hline \multirow[t]{2}{*}{1} & \multirow[t]{2}{*}{ HВP3070 } & \multirow[t]{2}{*}{$30: 70: 1: 1: 1$} & \multirow[t]{2}{*}{18} & \multirow[t]{2}{*}{63} & Peak 1 & 84.5 & 73.5 & 1.15 \\
\hline & & & & & Peak 2 & 19.4 & 10.4 & 1.86 \\
\hline 2 & HBP4060 & $40: 60: 1: 1: 1$ & 18 & 67 & $\begin{array}{c}\text { One broad } \\
\text { peak with a } \\
\text { shoulder }\end{array}$ & 24.2 & 9.0 & 2.67 \\
\hline \multirow[t]{2}{*}{3} & \multirow[t]{2}{*}{ HBP5050 } & \multirow[t]{2}{*}{$50: 50: 1: 1: 1$} & \multirow[t]{2}{*}{18} & \multirow[t]{2}{*}{60} & Peak 1 & 102.4 & 83.5 & 1.23 \\
\hline & & & & & Peak 2 & 24.4 & 15.3 & 1.59 \\
\hline
\end{tabular}

A: Feed molar ratio of [PAA]:[DMAEMA]:[DSDA]:[RAFT]:[ACVA] ${ }^{\text {B: Reaction time }}{ }^{\text {C. }}$ Weight average molecular weight ${ }^{D}$. Number average molecular weight $E$. Dispersity

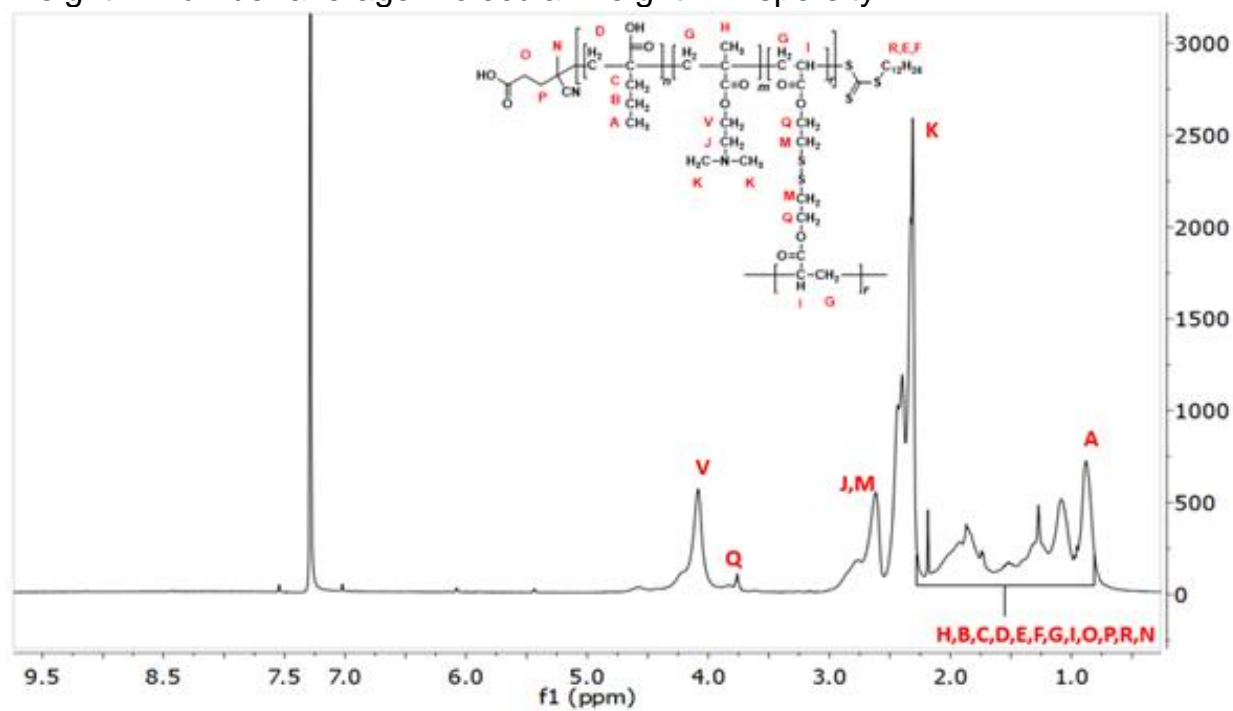

Figure 1: $400 \mathrm{MHz}{ }^{1} \mathrm{H}$ NMR spectrum for $\mathrm{HBP} 4060\left(\mathrm{CDCl}_{3}\right)$ (table 1) co-polymer composition $n, m, r$ can then be calculated from integral data. 
Table 2: Molar monomeric feed ratio and resulted copolymer compositions of poly(PAA-co-DMAEMA-co-DSDA) HBPs determined via ${ }^{1} \mathrm{H}$ NMR analysis.

\begin{tabular}{|c|c|c|}
\hline Sample & $F^{A}$ & $F^{B}$ \\
& PAA:DMAEMA:DSDA & PAA:DMAEMA:DSDA \\
\hline HBP3070 & $30: 70: 1$ & $46: 52: 2$ \\
\hline HBP4060 & $40: 60: 1$ & $54: 43: 3$ \\
\hline HBP5050 & $50: 50: 1$ & $55: 42: 3$ \\
\hline
\end{tabular}

A. Molar feed ratio for polymerization reactions. ${ }^{\text {B. }}$ Co-polymer composition determined by ${ }^{1} \mathrm{H}$ NMR analysis.

${ }^{1} \mathrm{H}$ NMR analysis of the polymers indicated that all three co-monomers had been incorporated into the overall polymer structure. It was found that the obtained copolymers contained a higher amount of PAA than the original feed in all three cases. Our previous experiments on the co-polymerizations of PAA and DSDA resulted in formation of gels with negligible amount of PAA within the polymer gel structure due to the relative low reactivity of PAA which can be attributed to the steric hindrance of both carboxyl group and propyl group for propagation steps[37]. Previous literatures have also reported low reactivity of the PAA monomer in both homo and co-polymerizations [34,53]. In this work, the introduction of monomer DMAEMA with the aim to succeed in co-polymerization of three monomer units forming HBP with both anionic and cationic characteristics, was performed. It is therefore interesting to see an increased PAA composition through ${ }^{1} \mathrm{H}$ NMR analysis, whilst also a higher \% of DSDA when compared to the feed. Furthermore, SEC results suggested more distinct two polymer populations for HBP3070 and HBP5050 (Table 1 and "Data in Brief article"[52]), whilst one broad peak with a shoulder for HBP4060 and a lower molecular weight although a much higher dispersity. These results are interesting, suggesting that the 40:60:1 composition produces polymers with a lower molecular weight however, the different populations are indistinguishable from one another. This results in a large dispersity and a broad peak. The large dispersity shown is uncharacteristic of the RAFT polymerization process, and could be due, in part, to the relatively low amount of RAFT agent used in the reaction when compared to the initiator. However, as previously stated the low reactivity of PAA lead to the ratio of $1: 1$ [RAFT]:[ACVA] being used as to allow the synthesis of a complex hyperbranched topology incorporating all monomers. It is hypothesized that a further increase of RAFT agent compared to initiator would allow for a decrease in molecular weight and a decrease in the dispersity value trending towards 1 , due to an increased controllability of the reaction. However, a decrease in the PAA overall composition \% in the polymer is possible due to a decrease in the low propagation rate.

Calculations for the copolymer composition were made using the following equations. For example, for the copolymer sample HBP4060, firstly, the integration value per proton is calculated via the sum of integrations for repeat units via peaks $A(P A A), K(D M A E M A)$ and $Q(D S D A)$ and this value is divided by the total number of hydrogens within the repeat units (13) (eq.2).

$$
\int \operatorname{per} H=\frac{\int A}{3 x}=\frac{\int K}{6 y}=\frac{\int Q}{4 z}
$$

Secondly, the ratio of $A, K$ and $Q$ and then formed from equation (2) is used to calculate the ratio of repeat units in the polymer (eq.3)

$$
\frac{1}{3}: \frac{1.62}{6}: \frac{0.06}{4}=0.33: 0.27: 0.015=33: 27: 1.5=66: 54: 3 \text { (eq. } 3 \text { ) }
$$

The sum of ratio repeat units is then used to calculate the overall polymer \% composition by the following method (eq.4).

$$
\% \text { composition }=\frac{66}{123}: \frac{54}{123}: \frac{3}{123} * 100 \%=54: 43: 3(4)
$$


Due to the nature of the work, in which endocytosis is facilitated at an approximate upper limit of $200 \mathrm{~nm}$ diameter of particle, all further work within the study was performed using HBP4060 as the polymer of choice. (Full HBP Integrations can be found in the corresponding "Data in brief" article[52].

\subsection{Assessment of pH Responsive properties and particle sizing}

It has been previously reported by Hoffman et al that PAA exhibits desirable $\mathrm{pH}$ responsive characteristics for targeted drug delivery, due to the relatively high pKa of the carboxylic acid moiety within the structure [54], promoting the observed sharp phase transitions at $\mathrm{pH} 6$ and below via Dynamic Light Scattering (DLS) particle sizing. This characteristic has led to a plethora of studies into the use of PAA for acid responsive smart materials. In this study, PAA based HBP4060 was tested for stimuli responsive characteristics in acidic conditions. It is known that a tumorous environment are more acidic in nature than healthy tissues, as a result of the Warburg effect[8], which initiates a response that generates an elevated production of lactic acid, which in turn lowers the $\mathrm{pH}$ of the cancerous tissues. The rationale behind the synthesis of $\mathrm{pH}$ responsive polymers is that their response can lead to endosome escape particularly towards early endosomes, which display a lower $\mathrm{pH}$ (ca. 6.5) than physiological conditions, as a result of the presence of proton pumps that are ATP dependent [55]. This allows for the provision of drugs to be delivered to intracellular compartments such as the nucleus.

Furthermore, the size of drug carriers is of paramount importance to allow for the exploitation of the enhanced permeation and retention effect (EPR)[56]. It has been shown that tumor cells can grow at their vastly enhanced speed because the vascular endothelial growth factor (VEGF) stimulates the production of the blood vessels to allow the delivery of resources required[57]. Indeed, the function of VEGF in the formation of many cancers has led to the use of VEGF-targeted chemotherapy[58]. The resultant EPR effect observed within tumorous sites allows for nanoparticles[59], liposomes[60] and macromolecular drugs[61] to accumulate within the cancerous tissues as oppose to their healthy counterparts. Whilst it may be the case that macromolecular species accumulate more frequently in these tissues, a "cap" of $200 \mathrm{~nm}$ must be placed on drug carriers for delivery purposes as to ensure that they readily facilitate endocytosis within the cells[62].

To study the effect of $\mathrm{pH}$ values on the sizes of our polymer samples in aqueous solutions, the copolymer was dissolved at $0.1 \%(\mathrm{w} / \mathrm{v})$ at three different $\mathrm{pH}$ values $(7.4,6.8$ and 5.4$)$ in distilled water. Visually no "clouding" of the solution was observed, suggesting the polymer solution was completely homogenous. For further study, particle-sizing measurements were performed, in order to assess possible changes in conformation of the polymer sample within this $\mathrm{pH}$ range. Particle sizing is a technique that relies on a laser beam bombarding particles and the resultant scatter of that beam is used to calculate particle size. Therefore, kinetic laws are paramount in understanding and interpreting the data. It is well known that particles in solution will collide with each other, indeed Einstein first theorized the idea of Brownian motion in 1905[63]. Therefore, in order to gain a true representation of particle size, the effects of convection must be negated, and the idea that "multiple scatter", in which the laser beam can experience interference from the dissolving media and possible aggregate formation must be taken into account. Interestingly, it was seen that from $\mathrm{pH}$ value 7.4 to 6.8 there was a decrease in particle size (from $100 \mathrm{~nm}$ to $75 \mathrm{~nm}$ ), before a large increase eclipsing both values at pH value 5.4, resulting in a particle size of $397 \mathrm{~nm}$, demonstrating the ability of the polymer to respond within solutions of different $\mathrm{pH}$ values. It was observed that within the measured polymer samples there were multiple population sizes, in all observed samples. Therefore, it could be theorized that the particles of small size are a true reflection of the polymer size, and the larger diameter reflects aggregation of the polymers within solution. (Table 3 )

Initially this decrease in particle size could be due to the effects of PAA. As previously stated upon protonation the polymer Poly (PAA) forms a compact structure, which would explain the decrease in particle size observed. However, the effects of DMAEMA cannot be neglected, and in the case of HBP4060 there is then a large increase in particle size which could be due to the tertiary amine. Due to the polyelectrolyte nature of the polymer, there will be transfer of charges across the backbone, from PAA to DMAEMA and vice-versa, therefore, zwitterionic character, could be a factor in morphological changes observed via DLS. In addition to this, a change from hydrophilic character of the polymer to a lipophilic like character could cause the formation of aggregates, thus inducing an increase in particle 
size when the $\mathrm{pH}$ is lowered to 5.4. This has been suggested by the observation of two distinctly different particle populations (this data can be found in the corresponding "Data in Brief article[52]" Additionally, it is plausible that when the HBP is switching from hydrophilic to hydrophobic character, water can be "trapped" inside of the nanostructure in hydrophilic pockets causing swelling, thus increasing particle size. It could obtain useful information about the sizes and morphology of the particles by performing Scanning Electron Microscopy (SEM) or Atomic Force Microscopy (AFM), however sample preparation for these techniques in general requires the sample in the solid state. With this in mind, the preparation of the nanoparticles and then subsequent evaporation of the solution media, would interfere with the particles true nature in solution and therefore would not represent their behavior truthfully. The act of evaporation and the heat required could induce aggregation of the particles, which previously may not occur, or the change of polymer topology thus, SEM and AFM were not performed in our study.

Table 3: DLS results for hyperbranched co-polymer HBP4060

\begin{tabular}{|c|c|}
\hline $\mathrm{pH}$ & Particle size $Z_{\text {Ave }}(\mathrm{nm})$ \\
\hline 7.4 & 100 \\
\hline 6.8 & 75 \\
\hline 5.4 & 337 \\
\hline
\end{tabular}

The size measuremnts for all samples showed a neglible error of $\pm<0.005 \mathrm{~nm}$.

\subsection{Conjugation of Folic Acid via NHS/DCC steglich esterification}

After the synthesis of HBPs, folic acid was conjugated onto the hyperbranched structure to create a nano-sized drug carrier for targeted drug delivery. We carried out the synthesis procedures using two different linkers with different chain length namely, ethylene diamine and $\mathrm{PEG}_{8}$ diamine.

Firstly, we performed conjugation using ethylene diamine via a "random conjugation" in which control over the selectivity of the reaction was limited, i.e. it was difficult to predict and control the amount of cross-linked polymer, cross-linked folate and polymer folate conjugates. Unsurprisingly, it was found that this method provided undesirable yield with a low folate conjugation on the resultant polymer, alongside crosslinked molecules. It is suspected that there are two possible scenarios which lead to the low conjugation in this reaction. Firstly there is no control over which $\mathrm{COOH}$ group is attacked, this could be either from the RAFT agent, the PAA moiety itself or folic acid. This lack of control can therefore yield any of: polymer-polymer conjugate (either RAFT-PAA or PAA-PAA conjugations), folic acid-folic acid conjugate and the desired folic acid-polymer conjugate. Secondly, aminolysis of the trithiocarbonate group could occur. As previously reported by Qiu and Winnick, introduction of a free amine group to their trithiocarbonate based RAFT agent allowed transformation of RAFT polymer end groups[38]. Due to the diamine nature of the linker employed, the free amine leftover could then be able to react again and further contribute to unwanted crosslinking. Therefore, control over the bio conjugation reaction was afforded, via first mono-BOC protecting the PEG diamine linker, followed by folate conjugation and subsequent deprotection to afford a folate linker conjugate with a free amine able to react with carboxylic acid moieties on the HBP leading to amide bond formation, and when compared to the former reaction, had more desirable yields, and folate conjugation, despite a tenfold decrease in moles of folate used for the latter (table 4). 

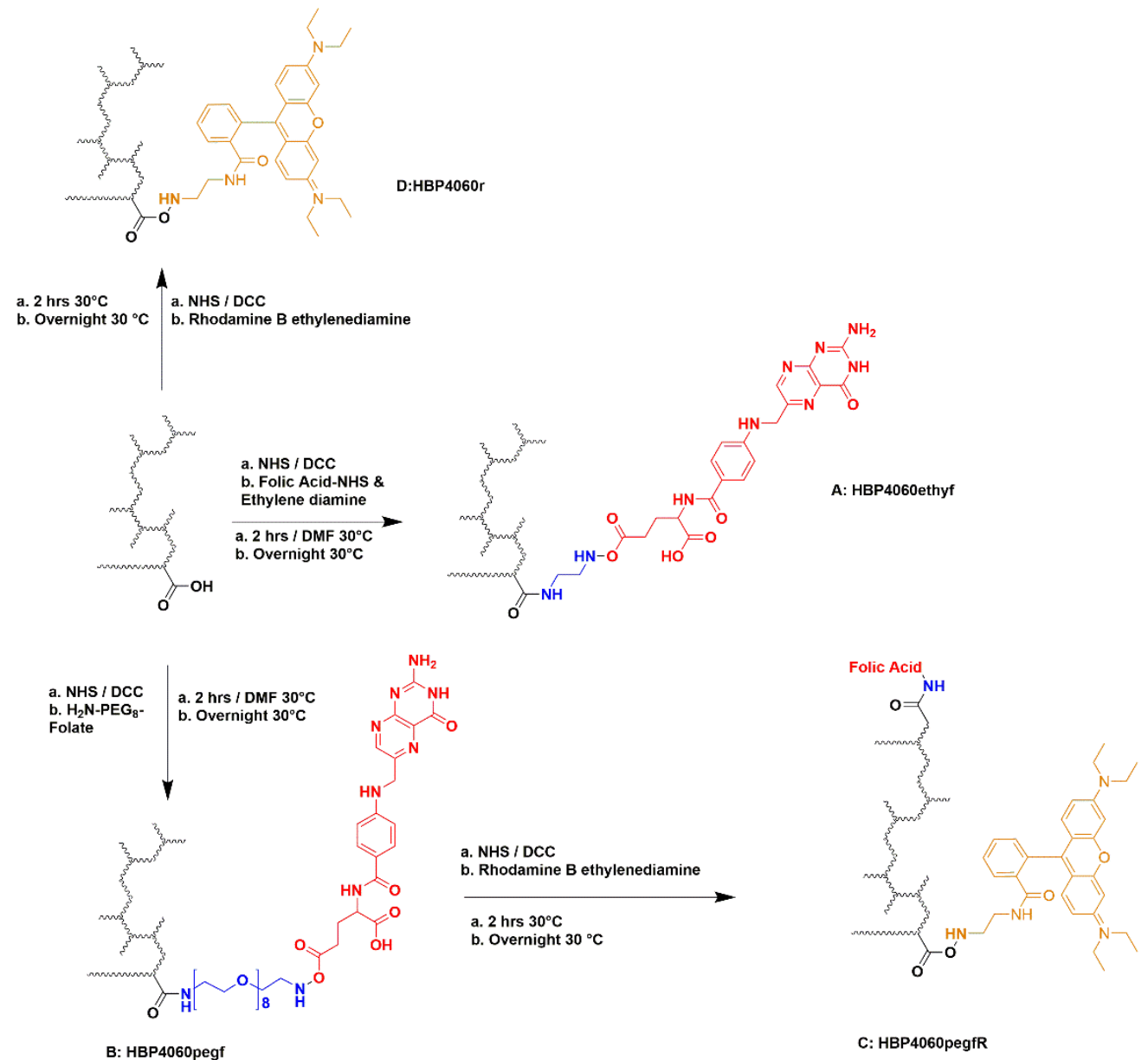

Polymer Backbone

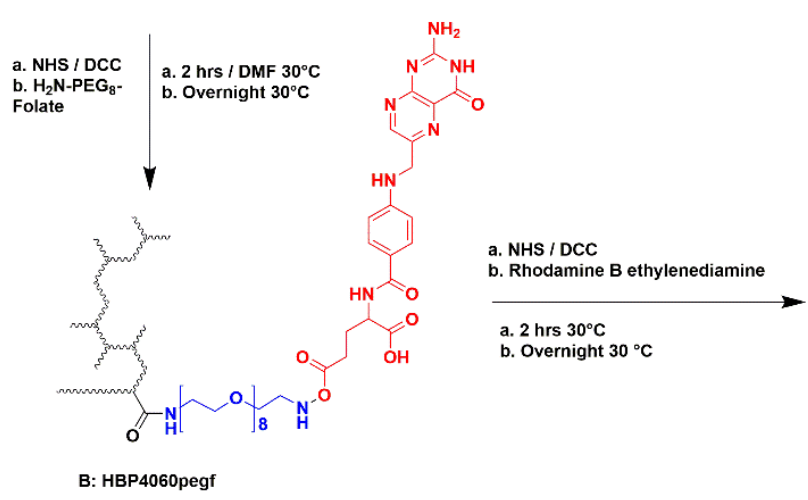

C: HBP4060pegfR

Scheme 2: Conjugation of ligands onto polymer backbone using NHS/DCC click chemistry. (A) Random conjugation with ethylene diamine and free folic acid (B) Controlled conjugation via $\mathrm{NH}_{2}-\mathrm{PEG}_{8}$-Folate, (C) further conjugation of rhodamine B ethylenediamine onto HBP4060 pegf and (D) the synthesis of HBP4060r. Linker synthesis $\left(\mathrm{H}_{2} \mathrm{~N}-\mathrm{PEG}\right.$-folate and Rhodamine $\mathrm{B}$ ethylene diamine) can be found in the corresponding "Data in Brief" article[52] .

Dialysis has been established as a robust method for the purification of large molecules, trapping them inside of the membrane whilst smaller molecules diffuse through via osmosis. Hereby, ensuring that only polymer conjugates remained in the tubing throughout. The use of the dialysis method with $2 \mathrm{KDa}$ cut off ensured that any unconjugated moieties, monomeric species and other small molecules were removed from the reaction mixture during purification. Furthermore, the use of a 5:95 DMF: $\mathrm{H}_{2} \mathrm{O}$ co-solvent system was employed to ensure organic molecules, such as unconjugated folic acid, solvate and diffuse through the membrane. Whilst the polymer folate conjugate are readily soluble in water alone, folic acid itself lends itself to acidic or aprotic media, such as DMSO or acetic acid, although was able to be solubilized in DMF for the interests of the Steglich esterification, hence the use of this organic within the dialysis solvent system. Interestingly, after the specified time period, it was found that a clumpy white powder had formed at the base of the dialysis tube, this was filtered via vacuum and was found to be dicyclohexylurea (DCHu) and $\mathrm{N}$-hydroxysuccinimide (NHS) leftover from the reaction, as confirmed by ${ }^{1} \mathrm{H}$ NMR spectroscopy, and therefore the solid was discarded as waste. The liquid (which contained the polymer folate conjugates) was then freeze dried and analyzed via ${ }^{1} \mathrm{H}$ NMR, with the ethylene conjugated complex forming a yellow powder, similar to that of the initial polymer, whereas through the controlled reaction the product was a much darker orange resembling the color of pure folic acid. Quantification of folate content via ${ }^{1} \mathrm{H}$ NMR (fig. 2) was found to be cumbersome (full integration data can be found in the corresponding "data in brief" article[52].) and in the case of HBP4060 ethyf no peaks were observed for folate, therefore, due to the UV active properties of folic acid through the 
aromatic motifs found within the structure, both polymer conjugates were subject to UV quantification methods.

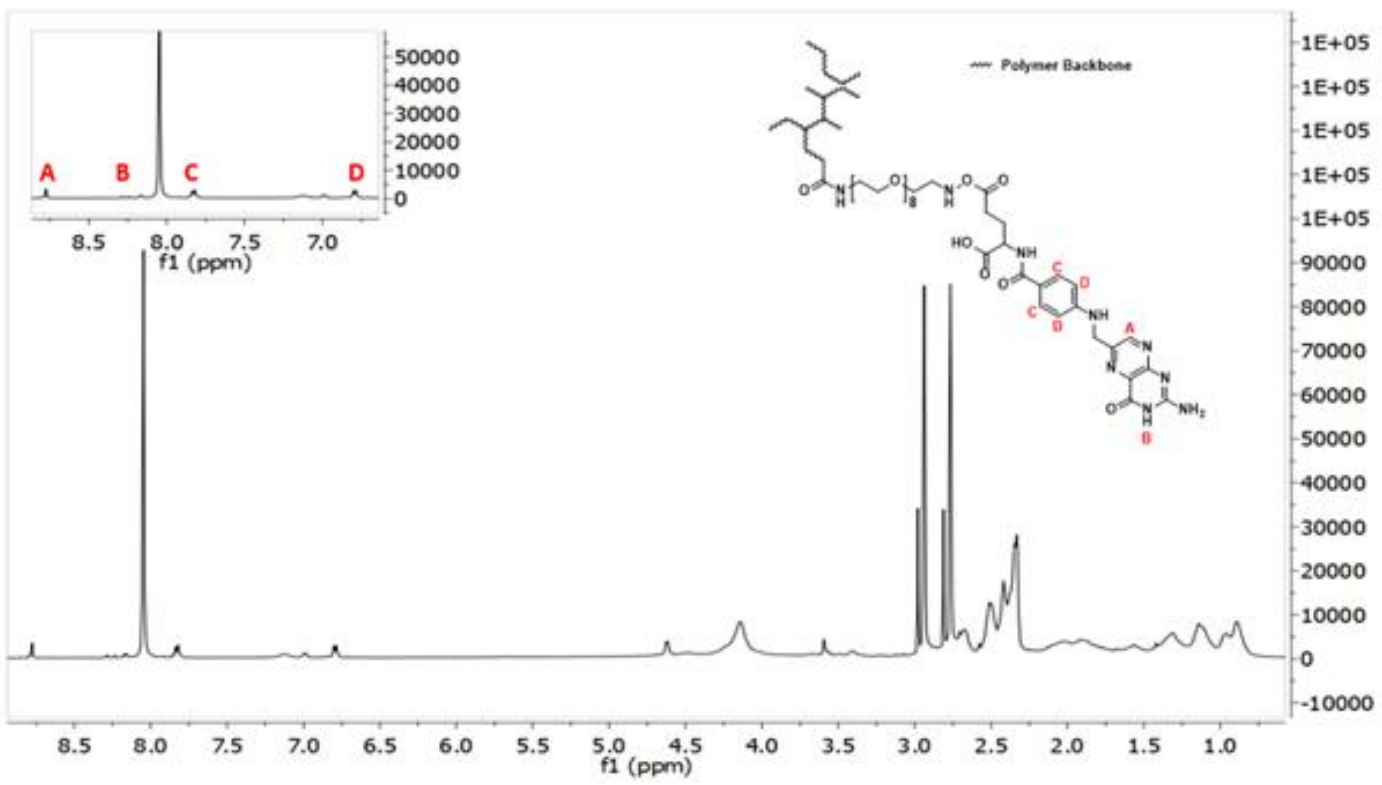

Figure 2: $500 \mathrm{MHz}{ }^{1} \mathrm{H}$ NMR HBP4060 ${ }_{\text {pegf }}$ (DMF-d7) post dialysis indicating conjugation of folic acid through the presence of aromatic peaks between 7-9ppm, with DMF peaks at 2.7, 3 and 8 ppm. Full polymer peak assignments can be found in figure 1 .

Sweeping through $270 \mathrm{~nm}$ - 500nm of unconjugated polymer and folate conjugated polymer, alongside folic acid, it was clear to see whether there was any folic acid conjugated onto the polymer (This data can be found in the corresponding "Data in Brief" article[52]). However, due to RAFT agent groups found on the terminus of the polymers interference with characteristic folic acid peaks around $280 \mathrm{~nm}-320 \mathrm{~nm}$ were present and therefore, quantification was performed utilizing absorbance at $362 \mathrm{~nm}$, which is indicative of folic acid, without interference from any polymeric species. RAFT agent alongside unlabeled polymer were ran as controls to identify peaks in which interference could occur, whilst it is possible to remove RAFT agent end groups to remove this interference there is also interference from the polymer backbone itself around $280 \mathrm{~nm}$. To further confirm the successful conjugation, the Ninhydrin test was employed to detect free primary amine groups in the samples according to the procedures described in the supporting information. The primary amine glycine was used as a control. It was found that HBP4060, HBP4060 ethyf $_{\text {and HBP4060 }}$ pegf all displayed a yellow color upon completion of the test, signifying that there are secondary amine present (both from DMAEMA and folic acid) and did not display the purple color associated with primary amines, such as in glycine, and thus conjugation was deemed to have been successful and complete.

Table 4: Quantification of Folic acid concentration for hyperbranched polymers HBP4060 ethyf and HBP4060 pegt

\begin{tabular}{|c|c|c|c|}
\hline Sample & $\begin{array}{c}\text { Folic acid molar eq. } \\
\text { to polymer } \\
\text { (in starting materials) }\end{array}$ & A.U 362nm & $\begin{array}{c}\mu \text { Mol } / \mathrm{mg} \text { (folate/polymer) } \\
\text { (in conjugated polymers) }\end{array}$ \\
\hline HBP4060 ethyf & 1.3 & 0.0062 & 0.17 \\
\hline HBP4060 pegf & 0.1 & 0.0500 & 1.12 \\
\hline
\end{tabular}

\section{4 Rhodamine conjugation and cellular uptake}

Rhodamine $B$ is a well-established fluorescent dye and when excited will fluoresce a bright red color, leading it a prime candidate for the visualization of Rhodamine B labelled polymers within cell structures through confocal microscopy. As previously mentioned, controlled conjugation of folic acid was 
performed via protection of diamine linker, amide bond formation with $\mathrm{COOH}$, subsequent deprotection and polymeric conjugation, again via amide bond formation. Conjugation of rhodamine $\mathrm{B}$ to the polymers followed this controlled conjugation procedure using ethylene diamine linker. Quantification of rhodamine dye on the polymers was achieved via UV-Vis spectroscopy measuring at rhodamine lambda max $554 \mathrm{~nm}$ (table 5).

Table 5: Quantification of Rhodamine contents on polymers via UV-Vis absorption spectrometry

\begin{tabular}{|c|c|c|}
\hline Sample & A.U 554nm & $\mathrm{nMol} / \mathrm{mg}$ (Rhodamine/polymer) \\
\hline HBP4060R & 0.3582 & 648.0 \\
\hline HBP4060 ${ }_{\text {pegfR }}$ & 0.0496 & 89.6 \\
\hline
\end{tabular}

Rhodamine labelled polymers, $\mathrm{HBP} 4060_{\text {pegf }}$ and $\mathrm{HBP} 4060_{\mathrm{R}}$, were dosed at cells within $100 \mathrm{\mu g}$ $10 \mu \mathrm{g} / \mathrm{ml}$ levels in order to assess their uptake into HeLa cells, within an hour. The HeLa cell line was chosen for these uptake studies because it is a well-established immortal cell line, derived from the cervical tumor of Henrietta Lacks. In addition, these cells overexpress the folate receptor, a common trait amongst tumorous tissues [57]. Concentrations for polymer dosage were chosen as to deduce the range in which the polymer displays a reduction in toxicity. Gemcitabine is usually administered via saline drip in a concentration of $1000 \mathrm{mg} / \mathrm{m}^{3}[64]$. Therefore, the upwards of $10 \mu \mathrm{g} / \mathrm{ml}$ of HBP was used for uptake evaluation. Polymers were sterilized using $0.2 \mu \mathrm{m}$ membrane filters. Due to the UV-light sensitive nature of folic acid[65,66], we were unable to sterilize using UV radiation, whilst excess heat, such as an autoclave, could breakdown the polymer structure. Membrane filtration was therefore used as the most appropriate form of sterilization for the polymers to eradicate microorganisms etc. from the chemical sample whilst keeping their chemical and physical integrity intact. Unfortunately, only dosage levels at $100 \mu \mathrm{g} / \mathrm{ml}$ could provide sufficient fluorescence for meaningful data to be extracted. Cells were fixed with 4\% PFA and nuclear structures were stained via DAPI. Confocal microscopy provided an analysis of polymer uptake and it is clear from the imagery produced, that free rhodamine at high dosage level $(210 \mathrm{nM} / \mathrm{ml})$ does not have a clear route of entry into the cellular structure. Leading to weaker than expected signals when excited. On the contrary, both polymers unlabeled with folate and PEG linked with folate, display fluorescent signals, with "hotspots", at a concentration of $100 \mu \mathrm{g} / \mathrm{ml}$. These hotspots could be indicative of endocytosis mechanisms but it is theorized that perhaps these are aggregated polymer molecules and therefore, a clear endocytosis mechanism cannot be confirmed at this stage (figure 3). Furthermore, localization of signal intensity suggests that once internalized into the cell there is an accumulation of polymer structure within the endoplasmic reticulum. With linkage of rhodamine and linker, the behavior of the polymer and the size of said polymer could also change, providing a barrier to entry due to rhodamine interactions with the cell membrane.

These results, although not quantitative, demonstrate that there is cellular internalization of polymeric species. Interestingly, it is shown that polymer free from folate is also being up taken into the cell. There was however, great difficulty obtaining images where cells had up taken HBP4060 pegfr. This could be attributed to the linker used ( $P E G_{8}$ diamine) leading to an increase in particle size, even before the addition of the rhodamine tag. (Table 6). Whilst the increase in size confirms conjugation of folate, it is known the upper limit for endocytosis is around $<200 \mathrm{~nm}$ for particles to be internalized. Images from Confocal microscopy displayed that the cells allow the uptake of both $\mathrm{HBP}_{4060_{R} \text { and }}$ HBP4060 pegfr. However, the size of HBP4060 pegiR nanoparticles needs to reduce, as any benefits of folate targeted drug delivery are lost due to the large size of these particles. However, the $\mathrm{pH}$ responsive nature of the structure in acidic media display an increasing particle size as the $\mathrm{pH}$ drops. Although, there is no longer the initial decrease in particle size as displayed in HBP4060. This could be due to the effects of folic acid targeting ligand conjugation, due to a reduced amount of free PAA functional groups as these were consumed during bio conjugation. Therefore, in an effort to reduce size and maintain the initial particle size decrease as a function of $\mathrm{pH}$, smaller linker such as a $\mathrm{PEG}_{4}$ and a much lowered ratio of polymer to folic acid should be used. Despite the folated variant of HBP4060 showing a decreased uptake in the cells observed, it is promising to see that uptake is facilitated for both sets of polymer HBP4060R and HBP4060 pegfr. 
Table 6: HBP4060 pegt particle sizing via DLS

\begin{tabular}{|c|c|}
\hline $\mathrm{pH}$ & Particle size ZAve $(\mathrm{nm})$ \\
\hline 7.4 & 882 \\
\hline 6.8 & 1195 \\
\hline 5.4 & 1160 \\
\hline
\end{tabular}

The size measurements of all samples showed a negligible error of $\pm<0.005 \mathrm{~nm}$. 


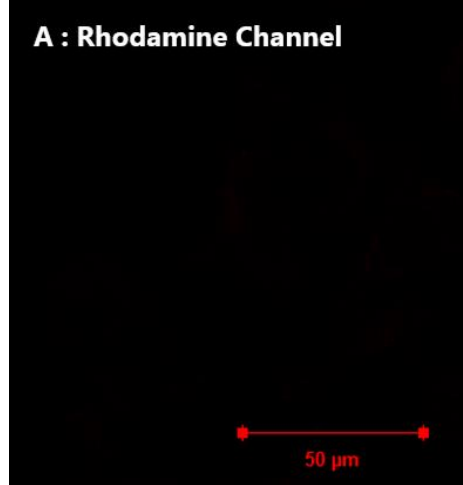

B: Rhodamine Channel

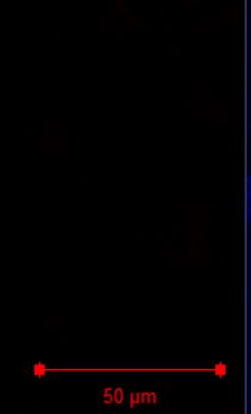

C: Rhodamine Channel

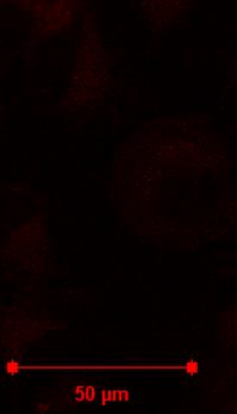

D: Rhodamine Channel

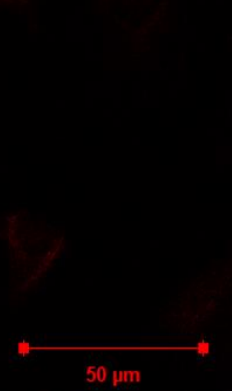

E: Rhodamine Channel
A: DAPI Channel

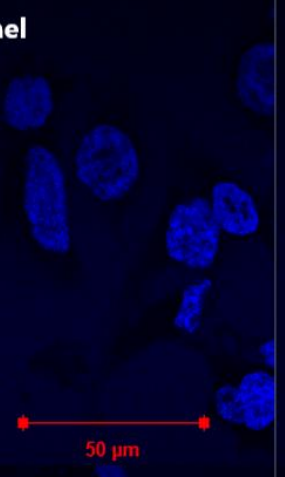

B: DAPI Channel

cher

C: DAPI Channel

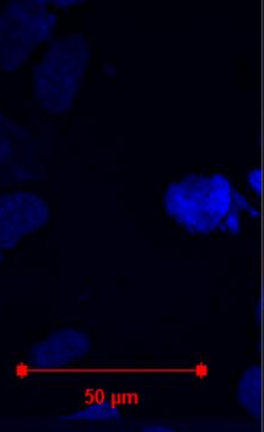

D: DAPI Channel

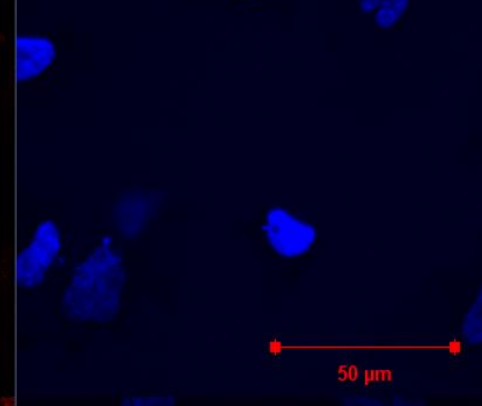

E: DAPI Channel

A: Channel Merge

B: Channel Merge

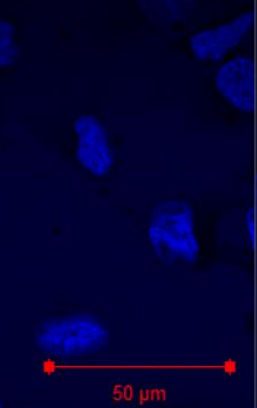

\section{C: Channel Merge}

D: Channel Merge

E: Channel Merge
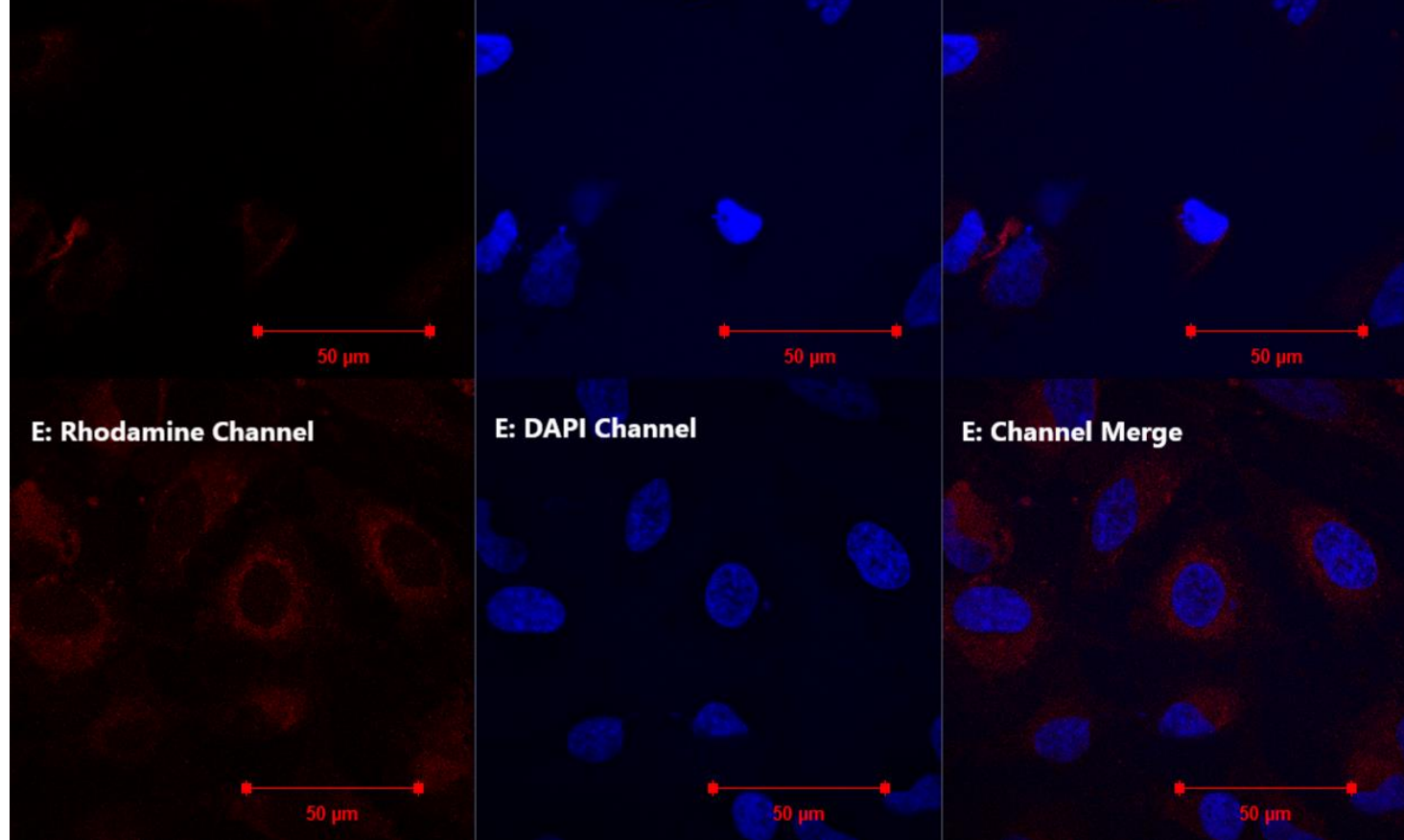
Figure 3: Confocal images at $63 x$ magnification for Rhodamine, DAPI and overlay. A. PBS; B. Water; C. Rhodamine $210 \mathrm{nM} / \mathrm{ml}$; D. HBP4060pegf $\mathrm{f}_{\mathrm{R}}$; E. HBP4060 $\mathrm{R}$. Where red staining indicates rhodamine and blue staining indicates DAPI nucleus staining.

\section{Conclusions}

We have successfully synthesized novel $\mathrm{pH}$ responsive hyperbranched polymers (HBPs) via Reversible Addition Fragmentation chain Transfer polymerization (RAFT). Feed ratios of co-monomers 2-propyl acrylic acid (PAA), 2-(dimethylamino) ethylmethacrylate (DMAEMA) and disulfanediylbis (ethane-2, 1-diyl) diacrylate (DSDA) were investigated to assess monomer reactivity and copolymer composition. Due to both PAA and DMAEMA functionality displayed on this HBP structure, there is the ability for both covalent linkage of functional moieties using carboxylic acid groups on PAA, whilst also ionic linkage with negatively charged species using tertiary amine on DMAEMA. This HBP polymer has been successfully conjugated with folic acid through either random linkage via ethylene diamine or controlled linkage through a folate-PEGs-amine. Characterization has been performed via ${ }^{1} \mathrm{H}$ NMR, SEC and UV-Vis. Dynamic Light Scattering (DLS) analysis was performed on both unlabeled HBP and folate conjugated HBP to analyze the $\mathrm{pH}$ responsive nature of the polymer at $\mathrm{pH} 7.4,6.8$ and 5.4. Size analysis confirmed that folate labelled HBP displayed radius at all pHs is greater $800 \mathrm{~nm}$ which leads this structure in the current form unsuitable for drug delivery, via folate mediated endocytosis, in which maximum particle size allowed is around $200 \mathrm{~nm}$. The study on cellular uptake of folated HBP polymer using the HeLa cell line has been performed utilizing confocal microscopy as a visualization technique alongside a rhodamine label which demonstrated uptake had taken place. Despite providing confirmation of both species being up taken, the difficulty in locating cells that had internalized folate labelled HBP confirmed the hypothesis that this HBP was too large for this purpose. Future work will consist of optimization of the polymer structures (composition, molecular weight and size) to increase uptake efficiency whilst also, comparative studies on viability between drug loaded and non-drug loaded forms of the polymer respectively, in order to assess the suitability of this structure as a candidate for target drug delivery carriers towards tumorous sites. Study on the cytotoxicity of these HBPs towards cell lines is also undergoing currently.

Supplementary Materials: The supplementary materials for this manuscript have been converted into the following "Data in Brief" article[52].

Author Contributions: All authors have contributed to this work and played important roles, in particular C. B. and H. T. The authors' contributions include in designing the structure and planning the experiments, C. B., H. T., E. H., and W.W.; in methodology and experiments, C.B., M. S. and X. W.; in data analysis and investigation, C.B. and H. T.; in writing-original draft preparation, C.B.; in writing-review and editing, C. B. and H. T.; in supervision, H. T. and E. H.; and in funding acquisition, H. T.

Funding: This research was funded by NRN LSNW, project number NRN511361 alongside Bangor University.

Acknowledgments: Particle sizing experiments were kindly run with access to facilities at Glyndwr University Wrexham under the guidance of Dr. lan Ratcliffe and Dr. Chandra Sedan. Thanks are given to Dr. Chris Staples and his group at the School of Medical science Bangor University for helpful and insightful discussions.

Conflicts of Interest: The authors declare no conflict of interest. The funders had no role in the design of the study; in the collection, analyses, or interpretation of data; in the writing of the manuscript, or in the decision to publish the results.

Data availability: The raw data required to reproduce these findings are available to download from [Mendeley Data]. The processed data required to reproduce these findings are available to download from [Mendeley Data)].

\section{References}

[1] L.A. Torre, F. Bray, R.L. Siegel, J. Ferlay, J. Lortet-tieulent, A. Jemal, Global Cancer Statistics, 2012, CA A Cancer J. Clin. 65 (2015) 87-108. doi:10.3322/caac.21262. 
[2] F. Bray, J. Ferlay, I. Soerjomataram, R.L. Siegel, A. Jemal, Global Cancer Statistics 2018: GLOBOCAN Estimates of Incidence and Mortality Worldwide for 36 Cancers in 185 Countries, CA. Cancer J. Clin. 0 (2018) 1-31. doi:10.3322/caac.21492.

[3] G. Can, M. Demir, O. Erol, A. Aydiner, A comparison of men and women's experiences of chemotherapyinduced alopecia, Eur. J. Oncol. Nurs. 17 (2013) 255-260. doi:10.1016/j.ejon.2012.06.003.

[4] G.A. Curt, W. Breitbart, D. Cella, J. Groopman, S. Horning, L. Itri, D. Johnson, C. Miaskowski, S. Scherr, R. Portenoy, N. Vogelzang, Impact of Cancer-Related Fatigue on the Lives of Patients: New Findings From the Fatigue Coalition, Oncologist. 5 (2000) 353-360. doi:10.1634/theoncologist.5-5-353.

[5] A. Coates, S. Abraham, S.B. Kaye, T. Sowerbutts, C. Frewin, R.M. Fox, M.H.N. Tattersall, On the receiving end-patient perception of the side-effects of cancer chemotherapy, Eur. J. Cancer Clin. Oncol. 19 (1983) 203-208. doi:10.1016/0277-5379(83)90418-2.

[6] Z.T. Han, Y.K. Tong, L.M. He, Y. Zhang, J.Z. Sun, T.Y. Wang, H. Zhang, Y.L. Cui, H.L. Newmark, a H. Conney, R.L. Chang, 12-O-Tetradecanoylphorbol-13-acetate (TPA)-induced increase in depressed white blood cell counts in patients treated with cytotoxic cancer chemotherapeutic drugs., Proc Natl Acad Sci USA. 95 (1998) 5362-5. doi:10.1073/pnas.95.9.5362.

[7] O. Warburg, Injuring of Respiration the Origin of Cancer Cells, Science (80-. ). 123 (1956) 309-14. doi:10.1126/science.123.3191.309.

[8] M.G. Vander Heiden, L.C. Cantley, C.B. Thompson, P. Mammalian, C. Exhibit, A. Metabolism, Understanding the Warburg Effect: Cell Proliferation, Science (80-. ). 324 (2009) 1029-1034. doi:10.1126/science.1160809.

[9] S.A. Kularatne, V. Deshmukh, M. Gymnopoulos, S.L. Biroc, J. Xia, S. Srinagesh, Y. Sun, N. Zou, M. Shimazu, J. Pinkstaff, S. Ensari, N. Knudsen, A. Manibusan, J.Y. Axup, C.H. Kim, V. V. Smider, T. Javahishvili, P.G. Schultz, Recruiting cytotoxic T cells to folate-receptor-positive cancer cells, Angew. Chemie - Int. Ed. 52 (2013) 12101-12104. doi:10.1002/anie.201306866.

[10] Z. Chen, H. Song, C. Su, W. Cui, B. Zhu, L. Liu, Z. Chen, L. Zhao, Folic Acid-Chitosan Conjugated Nanoparticles for Improving Tumor-Targeted Drug Delivery Folic Acid-Chitosan Conjugated Nanoparticles for Improving Tumor-Targeted Drug Delivery, Biomed Res. Int. 2013 (2013) 6. doi:10.1155/2013/723158.

[11] C.P. Leamon, J.A. Reddy, Folate-targeted chemotherapy, Adv. Drug Deliv. Rev. 56 (2004) 1127-1141. doi:10.1016/j.addr.2004.01.008.

[12] S. Wang, J. Luo, D.A. Lantrip, D.J. Waters, C.J. Mathias, M.A. Green, P.L. Fuchs, P.S. Low, Design and synthesis of [111/n]DTPA-folate for use as a tumor-targeted radiopharmaceutical, Bioconjug. Chem. 8 (1997) 673-679. doi:10.1021/bc9701297.

[13] A.R. Hilgenbrink, P.S. Low, Folate receptor-mediated drug targeting: From therapeutics to diagnostics, J. Pharm. Sci. 94 (2005) 2135-2146. doi:10.1002/jps.20457.

[14] G. Steinberg, R.F. Borch, Synthesis and evaluation of pteroic acid-conjugated nitroheterocyclic phosphoramidates as folate receptor-targeted alkylating agents, J. Med. Chem. 44 (2001) 69-73. doi:10.1021/jm000306g.

[15] Y. Patil, H. Shmeeda, Y. Amitay, P. Ohana, S. Kumar, A. Gabizon, Targeting of folate-conjugated liposomes with co-entrapped drugs to prostate cancer cells via prostate-specific membrane antigen (PSMA), Nanomedicine Nanotechnology, Biol. Med. $14 \quad$ (2018) 1407-1416. doi:10.1016/j.nano.2018.04.011.

[16] R.J. Lee, P.S. Low, Folate-mediated tumor cell targeting of liposome-entrapped doxorubicin in vitro, BBA - Biochim. Biophsica Acta. 1233 (1995) 134-144. doi:10.1016/0005-2736(94)00235-H. 
[17] M.O. Oyewumi, R.J. Mumper, Engineering tumor-targeted gadolinium hexanedione nanoparticles for potential application in neutron capture therapy, Bioconjug. Chem. 13 (2002) 1328-1335. doi:10.1021/bc025560x.

[18] M.A. Ward, T.K. Georgiou, Thermoresponsive polymers for biomedical applications, Polymers (Basel). 3 (2011) 1215-1242. doi:10.3390/polym3031215.

[19] M.E.H. El-Sayed, A.S. Hoffman, P.S. Stayton, Rational design of composition and activity correlations for pH-responsive and glutathione-reactive polymer therapeutics, J. Control. Release. 104 (2005) 417-427. doi:10.1016/j.jconrel.2005.01.009.

[20] S. Lv, Z. Tang, D. Zhang, W. Song, M. Li, J. Lin, H. Liu, X. Chen, Well-defined polymer-drug conjugate engineered with redox and $\mathrm{pH}$-sensitive release mechanism for efficient delivery of paclitaxel, J. Control. Release. 194 (2014) 220-227. doi:10.1016/j.jconrel.2014.09.009.

[21] P.C.A. Rodrigues, U. Beyer, P. Schumacher, T. Roth, H.H. Fiebig, C. Unger, L. Messori, P. Orioli, D.H. Paper, R. Mülhaupt, F. Kratz, Acid-sensitive polyethylene glycol conjugates of doxorubicin: Preparation, in vitro efficacy and intracellular distribution, Bioorganic Med. Chem. 7 (1999) 2517-2524. doi:10.1016/S0968-0896(99)00209-6.

[22] B.I. Voit, A. Lederer, Hyperbranched and Highly Branched Polymer Architectures - Synthetic Strategies and Major Characterization Aspects Hyperbranched and Highly Branched Polymer Architectures s Synthetic Strategies and Major Characterization Aspects, Chem. Rev. 109 (2009) 5924-5973. doi:10.1021/cr900068q.

[23] D. Wang, T. Zhao, X. Zhu, D. Yan, W. Wang, Bioapplications of hyperbranched polymers, Chem. Soc. Rev. 44 (2015) 4023-4071. doi:10.1039/c4cs00229f.

[24] A. Tochwin, A. El-Betany, H. Tai, K.Y. Chan, C. Blackburn, W. Wang, Thermoresponsive and reducible hyperbranched polymers synthesized by RAFT polymerisation, Polymers (Basel). 9 (2017) 1-15. doi:10.3390/polym9090443.

[25] D.A. Tomalia, J.M.J. Fréchet, Discovery of dendrimers and dendritic polymers: A brief historical perspective, J. Polym. Sci. Part A Polym. Chem. 40 (2002) 2719-2728. doi:10.1002/pola.10301.

[26] G. Pasut, F. Canal, L. Dalla Via, S. Arpicco, F.M. Veronese, O. Schiavon, Antitumoral activity of PEGgemcitabine prodrugs targeted by folic acid, J. Control. Release. 127 (2008) 239-248. doi:10.1016/j.jconrel.2008.02.002.

[27] D. Yang, W. Chen, J. Hu, Design of Controlled Drug Delivery System Based on Disulfide Cleavage Trigger, J. Phys. Chem. B. 118 (2014) 12311-12317.doi:10.1021/jp507763a

[28] X. Hu, G. Liu, Y. Li, X. Wang, S. Liu, Cell-penetrating hyperbranched polyprodrug amphiphiles for synergistic reductive milieu-triggered drug release and enhanced magnetic resonance signals, J. Am. Chem. Soc. 137 (2015) 362-368. doi:10.1021/ja5105848.

[29] S. Lee, K. Saito, H.R. Lee, M.J. Lee, Y. Shibasaki, Y. Oishi, B.S. Kim, Hyperbranched double hydrophilic block copolymer micelles of poly(ethylene oxide) and polyglycerol for $\mathrm{pH}$-responsive drug delivery, Biomacromolecules. 13 (2012) 1190-1196. doi:10.1021/bm300151m.

[30] B. Newland, H. Tai, Y. Zheng, D. Velasco, A. Di Luca, S.M. Howdle, C. Alexander, W. Wang, A. Pandit, A highly effective gene delivery vector - Hyperbranched poly(2-(dimethylamino)ethyl methacrylate) from in situ deactivation enhanced ATRP, Chem. Commun. 46 (2010) 4698-4700. doi:10.1039/c0cc00439a.

[31] H. Cao, C. Chen, D. Xie, X. Chen, P. Wang, Y. Wang, H. Song, W. Wang, A hyperbranched amphiphilic acetal polymer for pH-sensitive drug delivery, Polym. Chem. 9 (2018) 169-177. doi:10.1039/c7py01739a.

[32] D. Wang, Y. Jin, X. Zhu, D. Yan, Synthesis and applications of stimuli-responsive hyperbranched polymers, 
Prog. Polym. Sci. 64 (2017) 114-153. doi:10.1016/j.progpolymsci.2016.09.005.

[33] R. Dong, Y. Zhou, X. Zhu, Supramolecular dendritic polymers: From synthesis to applications, Acc. Chem. Res. 47 (2014) 2006-2016. doi:10.1021/ar500057e.

[34] H. Tai, C.L. Duvall, P.S. Stayton, A.S. Hoffman, W. Wang, pH-Responsive Hyperbranched Copolymers from One-pot RAFT Copolymerization of Propylacrylic Acid and Poly ( Ethylene Glycol Diacrylate ), Adv. Sci. Technol. 77 (2013) 333-342. doi:10.4028/www.scientific.net/AST.77.333.

[35] A. Katchalsky, H. Eisenberg, Molecular weight of polyacrylic and polymethacrylic acid, J. Polym. Sci. 6 (1951) 145-154. doi:10.1002/pol.1951.120060202.

[36] T. Swift, L. Swanson, M. Geoghegan, S. Rimmer, The pH-responsive behaviour of poly(acrylic acid) in aqueous solution is dependent on molar mass, Soft Matter. 12 (2016) 2542-2549. doi:10.1039/c5sm02693h.

[37] X. Yin, A.S. Hoffman, P.S. Stayton, Poly ( N -isopropylacrylamide- c o -propylacrylic acid) Copolymers That Respond Sharply to Temperature and pH, Biomacromolecules. 7 (2006) 1381-1385. doi:10.1021/bm0507812.

[38] X.P. Qiu, F.M. Winnik, Facile and efficient one-pot transformation of RAFT polymer end groups via a mild aminolysis/michael addition sequence, Macromol. Rapid Commun. 27 (2006) 1648-1653. doi:10.1002/marc.200600436.

[39] M. Zheng, F. Aslund, G. Storz, Activation of the OxyR Transcription Factor by Reversible Disulfide Bond Formation, Science (80-. ). 279 (1998) 1718-1721.doi:10.1126/science.279.5357.1718

[40] G. Liu, X. Wang, J. Hu, G. Zhang, S. Liu, Self-immolative polymersomes for high-efficiency triggered release and programmed enzymatic reactions, J. Am. Chem. Soc. 136 (2014) 7492-7497. doi:10.1021/ja5030832.

[41] T. Zhao, H. Zhang, B. Newland, A. Aied, D. Zhou, W. Wang, Significance of branching for transfection: Synthesis of highly branched degradable functional poly(dimethylaminoethyl methacrylate) by vinyl oligomer combination, Angew. Chemie - Int. Ed. 53 (2014) 6095-6100. doi:10.1002/anie.201402341.

[42] K. Matyjaszewski, Atom Transfer Radical Polymerization (ATRP): Current status and future perspectives, Macromolecules. 45 (2012) 4015-4039. doi:10.1021/ma3001719.

[43] J. Xia, K. Matyjaszewski, Controlled/"Living" Radical Polymerization. Atom Transfer Radical Polymerization Catalyzed by Copper(I) and Picolylamine Complexes, J. Am. Chem. Soc. 117 (1995) 5614-5615. doi:10.1021/ma981694n.

[44] H. Tai, W. Wang, T. Vermonden, F. Heath, W.E. Hennink, C. Alexander, K.M. Shakesheff, S.M. Howdle, Thermoresponsive and photocrosslinkable PEGMEMA-PPGMA-EGDMA copolymers from a one-step ATRP synthesis, in: Biomacromolecules, 2009: pp. 822-828. doi:10.1021/bm801308q.

[45] C.J. Hawker, A.W. Bosman, E. Harth, New polymer synthesis by nitroxide mediated living radical polymerizations, Chem. Rev. 101 (2001) 3661-3688. doi:10.1021/cr990119u.

[46] V. Sciannamea, R. Jérôme, C. Detrembleur, In-situ nitroxide-mediated radical polymerization (NMP) processes: Their understanding and optimization, Chem. Rev. 108 (2008) 1104-1126. doi:10.1021/cr0680540.

[47] G. Moad, E. Rizzardo, S.H. Thang, Living Radical Polymerization by the RAFT Process-A Third Update, Aust. J. Chem. 65 (2012) 985-1076. doi:10.1071/CH12295.

[48] M.H. Stenzel, RAFT polymerization: An avenue to functional polymeric micelles for drug delivery, Chem. Commun. (2008) 3486-3503. doi:10.1039/b805464a. 
[49] D. Zhou, Y. Gao, A. Sigen, Q. Xu, Z. Meng, U. Greiser, W. Wang, Anticancer Drug Disulfiram for in Situ RAFT Polymerization: Controlled Polymerization, Multifacet Self-Assembly, and Efficient Drug Delivery, ACS Macro Lett. 5 (2016) 1266-1272. doi:10.1021/acsmacrolett.6b00777.

[50] Y. Zhao, Z.H. Houston, J.D. Simpson, L. Chen, N.L. Fletcher, A. V. Fuchs, I. Blakey, K.J. Thurecht, Using Peptide Aptamer Targeted Polymers as a Model Nanomedicine for Investigating Drug Distribution in Cancer Nanotheranostics, Mol. Pharm. 14 (2017) 3539-3549. doi:10.1021/acs.molpharmaceut.7b00560.

[51] Y. Huang, R. Sun, Q. Luo, Y. Wang, K. Zhang, X. Deng, W. Zhu, X. Li, Z. Shen, In situ fabrication of paclitaxel-loaded core-crosslinked micelles via thiol-ene "click" chemistry for reduction-responsive drug release, J. Polym. Sci. Part A Polym. Chem. 54 (2015) 99-107. doi:10.1002/pola.27778.

[52] C. Blackburn, H. Tai, M. Salerno, X. Wang, E. Hartsuiker, W. Wang, Data presenting the synthesis of three novel stimuli responsive hyperbranched polymers synthesised via RAFT polymerisation and the bio conjugation of folic acid, Data Br. (2019).

[53] N. Murthy, J.R. Robichaud, D.A. Tirrell, P.S. Stayton, A.S. Hoffman, The design and synthesis of polymers for eukaryotic membrane disruption, J. Control. Release. 61 (1999) 137-143. doi:10.1016/S01683659(99)00114-5.

[54] and P.S.S. Jessica C. Garbern, Allan S. Hoffman, Injectable pH- and temperature-responsive poly(Nisopropylacrylamide-co-propylacrylic acid) copolymers for delivery of angiogenic growth factors, Biomacromolecules. 11 (2011) 1833-1839. doi:10.1021/bm100318z..

[55] Y.B. Hu, E.B. Dammer, R.J. Ren, G. Wang, The endosomal-lysosomal system: From acidification and cargo sorting to neurodegeneration, Transl. Neurodegener. 4 (2015) 1-10. doi:10.1186/s40035-015-00411.

[56] J. Fang, H. Nakamura, H. Maeda, The EPR effect: Unique features of tumor blood vessels for drug delivery, factors involved, and limitations and augmentation of the effect, Adv. Drug Deliv. Rev. 63 (2011) 136-151. doi:10.1016/j.addr.2010.04.009.

[57] H.L. Goel, A.M. Mercurio, VEGF targets the tumour cell, Nat. Rev. Cancer. 13 (2013) 871-882. https://doi.org/10.1038/nrc3627.

[58] L.M. Ellis, D.J. Hicklin, VEGF-targeted therapy: mechanisms of anti-tumour activity, Nat. Rev. Cancer. 8 (2008) 579-591. https://doi.org/10.1038/nrc2403.

[59] S. Acharya, S.K. Sahoo, PLGA nanoparticles containing various anticancer agents and tumour delivery by EPR effect, Adv. Drug Deliv. Rev. 63 (2011) 170-183. doi:10.1016/j.addr.2010.10.008.

[60] K. Maruyama, Intracellular targeting delivery of liposomal drugs to solid tumors based on EPR effects, Adv. Drug Deliv. Rev. 63 (2011) 161-169. doi:10.1016/j.addr.2010.09.003.

[61] R. Duncan, The dawning era of polymer therapeutics, Nat. Rev. Drug Discov. 2 (2003) 347. https://doi.org/10.1038/nrd1088.

[62] J. Rejman, V. Oberle, I.S. Zuhorn, D. Hoekstra, Size-dependent internalization of particles via the pathways of clathrin- and caveolae-mediated endocytosis, Biochem. J. 377 (2004) 159-169. doi:10.1042/BJ20031253.

[63] A. Einstein, On the Motion of Small Particles Suspended in a Stationary Liquid, as Required by the Molecular Kinetic Theory of Heat, Ann. Phys. 322 (1905) 549-560. doi:10.1002/andp.19053220806.

[64] T. Shibata, T. Ebata, K. ichi Fujita, T. Shimokata, O. Maeda, A. Mitsuma, Y. Sasaki, M. Nagino, Y. Ando, Optimal dose of gemcitabine for the treatment of biliary tract or pancreatic cancer in patients with liver dysfunction, Cancer Sci. 107 (2016) 168-172. doi:10.1111/cas.12851. 
[65] M. Jamil Akhtar, M. Ataullah Khan, I. Ahmad, Identification of photoproducts of folic acid and its degradation pathways in aqueous solution, J. Pharm. Biomed. Anal. 31 (2003) 579-588. doi:10.1016/S07317085(02)00724-0.

[66] M.J. Akhtar, M.A. Khan, I. Ahmad, Photodegradation of folic acid in aqueous solution, J. Pharm. Biomed. Anal. 19 (1999) 269-275. doi:10.1016/S0731-7085(98)00038-7. 